\title{
HIV-2 and its role in conglutinated approach towards Acquired Immunodeficiency Syndrome (AIDS) Vaccine Development
}

\author{
Batul Diwan*, Rupali Saxena and Archana Tiwari
}

\begin{abstract}
Acquired Immunodeficiency Syndrome (AIDS) is one of the most critically acclaimed endemic diseases, caused by two lentiviruses HIV-1 and 2. HIV-2 displays intimate serological and antigenic resemblance to Simian Immunodeficiency Virus (SIV) along with less pathogenicity, lower infectivity and appreciable cross reactivity with HIV-1 antigens. The present era is confronted with the challenge to fabricate a vaccine effective against all clades of both the species of HIV. But vaccine development against HIV-1 has proven highly intricate, moreover the laborious and deficient conventional approaches has slackened the pace regarding the development of new vaccines. These concerns may be tackled with the development of HIV-2 vaccine as a natural control of HIV-1 that has been found in ancestors of HIV-2 i.e. African monkeys, mangabeys and macaques. Thereby, suggesting the notion of cross protection among HIV-2 and HIV-1. Assistance of bioinformatics along with vaccinomics strategy can bring about a quantum leap in this direction for surpassing the bottleneck in conventional approaches. These specifics together can add to our conception that HIV-2 vaccine design by in silico strategy will surely be a constructive approach for HIV-1 targeting.
\end{abstract}

Keywords: Human Immunodeficiency Virus-2, Vaccine Development, Bioinformatics, Vaccinomics

\section{Introduction}

The first acknowledged case that marked the commencement of AIDS dates back to the late 19th century and ever since it has been regarded as the most devastating pandemic with no definite cure available till date. It is the final stage of an immunodeficiency disorder caused by a retrovirus called Human Immunodeficiency Virus (HIV) (Amadi et al. 2008). The origin of HIV, on the basis of intimate similarity is related to another kind of virus which infected monkeys, known as the Simian Immunodeficiency Virus (SIV) (Worobey et al. 2010).

AIDS is characterized by the selective targeting of the CD4+/CD8+ $\mathrm{T}$ cells by HIV which fatally impairs the immune system. The window period for this retrovirus may last from several weeks to few months altogether before the seroconversion (detection of earliest antibodies in blood serum raised against HIV) (Taylor 2003). However, a person is said to be diagnosed with AIDS, only

\footnotetext{
* Correspondence: diwan.batul@gmail.com

School of Biotechnology, Rajiv Gandhi Proudyogiki Vishwavidyalaya, Bhopal, MP, India
}

\section{Springer}

(c) 2013 Diwan et al.; licensee Springer. This is an Open Access article distributed under the terms of the Creative Commons Attribution License (http://creativecommons.org/licenses/by/2.0), which permits unrestricted use, distribution, and reproduction in any medium, provided the original work is properly cited.

\section{Human Immunodeficiency Viruses $1 \& 2$}

There are two closely related human lentiviruses causing AIDS, referred to as HIV-1 and HIV-2 (Adam et al. 2007). Although HIV-1 is more common and prevalent species of HIV, HIV-2 is relatively new and was discovered in West Africa in 1986 (Clavel et al. 1986). It has evolved as a result of independent cross species transmission events from sooty mangabeys to humans (Clavel et al. 1986). It is found to be more widespread in West Africa, India and Europe infecting about 1 to 2 million individuals (de Silva et al. 2008). Even though there are few differences between HIV-1 and HIV-2 (Table 1), both are perilous. HIV-1 and 2 shares various biological and genetic properties such as genome structures, mechanism of trans-activation and manner of $\mathrm{CD} 4+\mathrm{T}$ cell 
Table 1 Comparison of HIV-1 and HIV-2 characteristics

\begin{tabular}{lll}
\hline CHARACTERISTICS & HIV-1 & HIV-2 \\
\hline Infectivity & High & Low \\
\hline Virulence & High & Low \\
\hline Heterosexual Spread & Higher & Lower \\
\hline Vertical Transmission & $20-25 \%$ & $\leq 5 \%$ \\
\hline Genetic Diversity & - & Lower \\
\hline Prevalence & Global & West Africa \\
\hline Origin & Common Chimpanzee & Sooty Mangabey \\
\hline Time to Aids & $\leq 10$ Years & $\geq 20$ Years \\
\hline
\end{tabular}

depletion (Guyader et al. 1987; Levy 1993). The virulence properties of HIV-2 vary appreciably from HIV-1 and may range from comparative attenuation in certain individuals to elevated pathogenicity in others (Reeves \& Doms 2002).

Although both viruses lead to immunodeficiency but (Clavel et al. 1986) HIV-2 in contrast to HIV-1 exhibits lesser rates of sexual transmission, slower disease progression, longer clinical latency periods lower viral load in the asymptomatic stage (Sousa et al. 2002) and significantly lower vertical and horizontal transmission rates (Reeves \& Doms 2002).

Strains of HIV-1 are classified as Group M, Group N, Group O and Group P. Out of these, only group $\mathrm{M}$ is broadly dispersed in the world whereas, HIV 2 has six subtypes (or clades) ranging from $\mathrm{A}$ to $\mathrm{F}$ and of these, subtype A is most prevalent (De Cock et al. 1993; Reeves \& Doms 2002). Studies have revealed a relatively resistant response of HIV-2 infected individual towards consequent HIV-1 infection (De Cock et al. 1993; Reeves \& Doms 2002). The similarities that exist between HIV-1 and HIV-2 can be exploited for the development of a prospective vaccine which can potentially target HIV-1. The underlying principle behind this approach is to formulate a vaccine based on the conserved genetic sequences that are present in HIV-2. As previously mentioned, HIV-2 infected individual provides a cross protection against HIV-1. So, it is thought that a vaccine developed against HIV-2 can also show the caliber of targeting HIV-1 (which is difficult to target otherwise due to its highly mutative nature). This can be achieved with the help of upcoming bioinformatic strategies which is dealt in Later Section. The main advantage of such an approach is that it saves a lot of time and energy that is indispensably called for any wet lab approach based on a similar concept.

\section{Genetics}

Although HIV-1 and HIV-2/SIV groups of viruses might have genetically diverged from each other about 50 to 60 years ago (Chen et al. 1996) but they still show a genetic similarity of about 40-50 percent (Sourial et al.
2005). Primary, regulatory and accessory genes in HIV-2 are similar to that of HIV-1 with slight differences that are discussed below:

A. Polymerase gene (pol): Three proteins are encoded by pol of HIV-2: endonuclease/integrase (IN), protease (PR) and reverse transcriptase (RT), which also has RNaseH activity. Studies demonstrate that HIV-2 pol shows comparable error prone propensity as that of HIV-1 (Bakhanashvili \& Hizi 1992) on the other hand, its $\mathrm{RNaseH}$ activity is reported to be lesser by almost 10-folds than HIV-1 enzyme (Hizi et al. 1991). B. Structural Genes ( $g a g$ \& env): Extremely conserved gag proteins are basically same for both HIV-1 and HIV-2 (Voss et al. 1992). A myristoylated 55-kDa precursor cleaved by the viral protease generates the capsid protein p24 (CA); the nucleocapsid protein p7 (NC); the matrix protein p17 (MA); p1; p2; and p6. HIV-2's envelope glycoprotein precursor is somewhat smaller in contrast to HIV-1, hence at times it is designated with lower sizes (i.e. gp140-145, gp105-110 and gp32-40 respectively).

C. Regulatory and Accessory Genes: RNA processing or splicing is a vital control component apart from the long terminal repeat (LTR) regions at the ends of the viral genome containing crucial sequences for transcriptional activation and termination. As compared to HIV-1, HIV-2 has less responsive LTR to cellular activation signals and has dissimilar response elements (Popper et al. 2000). Also transcriptional activation requires additional factors. These differences along with lower CD4 affinity seen with HIV-2's gp120 may account for the reason that makes HIV-2 infected individuals to have a lower viral load than those infected with HIV-1 (Sousa et al. 2002). Also HIV-2 shows enhanced sensitivity to neutralization due to its ability to infect host cell independent of CD4 interaction (Figure 1 \& 2) (Reeves \& Doms 2002).

Studies also verify that among HIV-1 and HIV-2 infected individuals, T4 lymphocyte counts and T4:T8 ratios emerge to be declined less significantly in HIV-2 than in HIV-1 infected individuals (Kanki \& Meloni 2004).

Genetic details of HIV-2 reveal many important factors responsible for slow progression and less virulent nature of HIV-2. Not only structural but also the regulatory genes demonstrate varied activity and its host attachment affinity is also lower compared to HIV-1 which might be the prime reason of HIV-2's reduced virulent nature.

These data all together indicate that it is comparatively easier to target HIV-2 than HIV-1. Talking about immunity against HIV-2, humoral and T-cell immune response decline slowly compared to HIV-1 infected individual. 


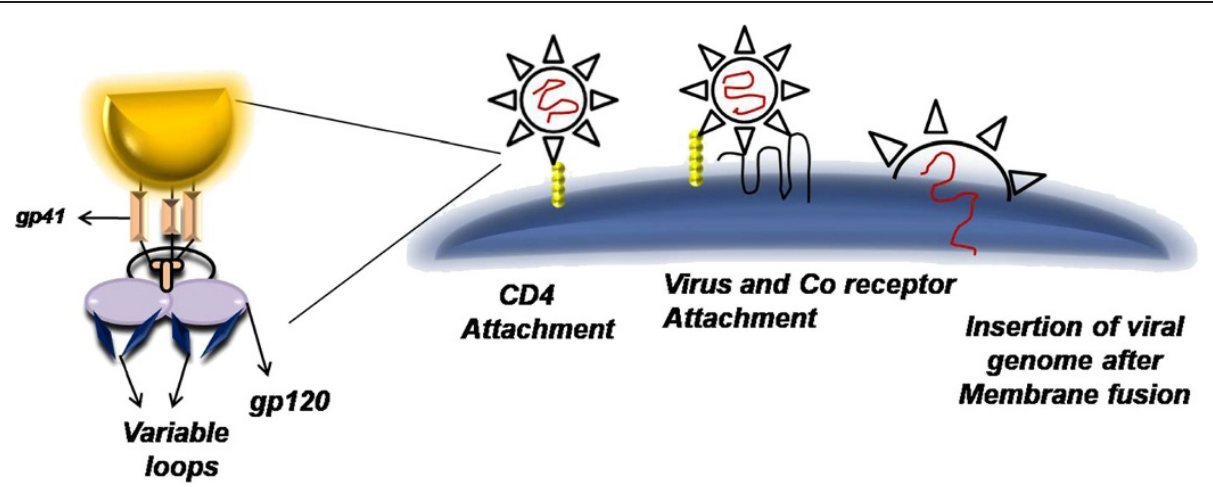

Figure 1 CD4 Dependent infection: Interaction between CD4 on T cell and viral gp120 leads to conformational changes in Env which further brings about interaction between co receptor and virus which further leads to fusion of viral membrane and insertion of viral genome in a host cell.

So for vaccine design, immune response against HIV-2 can be studied which can offer hints regarding the way immune system reacts on its exposure.

\section{Immunity}

HIV-2 illustrates attenuated infectivity which has constantly been a subject of curiosity among researchers for understanding its immunopathogenesis. Also, studies highlight the fact that the strong antibody response is generated by infected people against antigens encoded by gag, pol, and env (Chanock et al. 1987; Girard \& Valette 1988). The broadness of neutralizing antibody reaction against HIV-2 is divergent from that of HIV-1 (Fenyo \& Putkonen 1996). Cervicovaginal secretions of infected women demonstrated that one-third of them generated IgA response to HIV-2 envelope antigens confirming lesser viral replication as compared to HIV-1. HIV-2 infected individuals also show prominent crossreactivity by IgG and IgA against heterologous envelope antigens in contrast to HIV-1 for this compartment (Belec et al. 1996). This might be the rationale behind dissimilar heterosexual transmission rates for one type of HIV in individuals infected by other type. This elucidation maintains the belief that HIV-2 infection protects against subsequent HIV-1 infection but not the vice versa. While some predicted the exact contrary detail that HIV-2 infection does not protect against consecutive HIV-1 infections (Greenberg 2001; Schim van der Loeff et al. 2001). In depth studies on HIV-1 \& HIV2 is required to conclude this debate and reveal several hidden facts. Nevertheless, these perceptions of cross protection among HIV-2 and HIV-1 can add to our comprehension whether viral variability can be conquered for the design of broadly reactive vaccine candidate against all subtypes (or clades).

\section{Necessity of Vaccine}

Successful anti-HIV vaccine is an immediate need considering its pandemic in certain regions of the world including West Africa, China and Southeast Asia to halt this wave of spread. But its development has been a major challenge till date for scientists as HIV demolishes immune system intended to fight against it, also its genetic material remains in dormant form and thus escapes the immune system. It has quite a few subtypes each differing from one another and even in each subtypes it

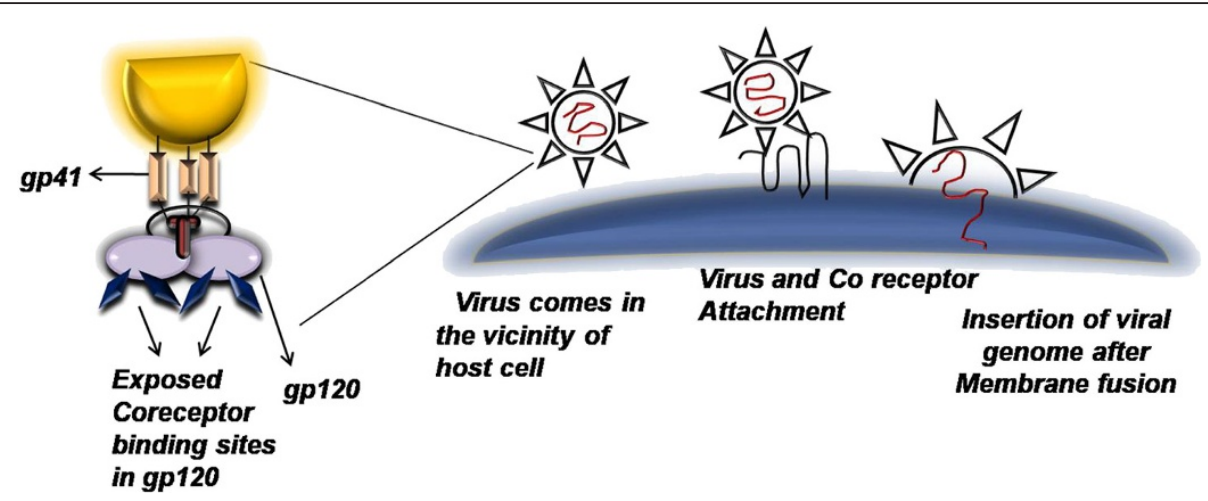

Figure $\mathbf{2}$ CD4 Independent infection: Interaction takes place directly between virus and co receptors to trigger membrane fusion and genome insertion process. 
constantly mutates itself and lastly no satisfactory animal model exist for trials. However, non human primates may possibly appear as a significant option (Bernstein 2010). Even after the advancement in medication pattern new infections still persists and an effective vaccine is required to completely stop its spread. Till date more than 60 phase I, II and III trials are going on around the world but a truly effective vaccine is still far away from a stage where it can be said as achieved.

Hopes still persist for discovery of vaccine as many researches and findings elucidate production of broadly neutralizing antibodies targeting different types of HIV which can be the basis for new research in the vaccine development.

\section{Conventional Attempts}

Numerous ongoing researches have taken into account various aspects for targeting HIV-2 each one of which can notably contribute towards its targeting.

Five major subtypes (or clades) of HIV-2 from A to E have already been reported to exist in certain human population (Gao et al. 1994). But a new highly divergent HIV-2 subtype (or clade) designated as F is the recent addition to the presently existing classes supporting the belief that new HIV-2 subtypes evolve from independent cross-species transmission of $\mathrm{SIV}_{\mathrm{sm}}$ to the human population (Smith et al. 2008). Comparative analysis of SIV $_{\mathrm{sm}}$ and HIV-2 with HIV-1 in the macaques model demonstrated that pathogenic $\operatorname{SIV}_{\mathrm{sm}}$ infection was neutralization resistant similar to HIV-1 infection in humans. On contrary, HIV-2 infected macaques remain susceptible to neutralization and exhibit cross reactivity on account of its steady biological properties (Laurén et al. 2006).

Vaccine trials carried out in macaque's model revealed that active immunization with iscoms (immune stimulating complex) using native inactivated viral proteins followed by iscom coupled V3 derived peptide booster doses induced protective immunity against HIV-2 infection in cynomologus monkeys (Putkonen et al. 1994). In another study, immunogenicity and neutralizing response of recombinant envelope proteins derived from the lone administration of reference primary HIV-2ALI (one kind of HIV-2 isolate) or in different prime-boost combinations in the mouse model was investigated. It was found that broadly reactive HIV-2 Nabs can be obtained by using a vaccinia virus vector-prime/rpC2-C3 (recombinant peptide containing C2 V3 C3 envelope region) boost immunization strategy which suggested a potential relationship between escape to neutralization (Marcelino et al. 2010). Similarly, the efficacy of a recombinant HIV-2 canarypox (ALVAC HIV-2 which uses canarypox virus which cannot harm human) vaccine given alone or in combination with HIV-2 envelope gp125 or HIV-2 V3 synthetic peptides was inspected in
14 cynomologus monkeys. Four out of ten monkeys immunized with ALVAC HIV-2 plus HIV-2 gp125 or V3 peptides were found to be protected (Andersson et al. 1996).

The aforementioned studies indicate the existence of certain conserved regions in HIV-2 against which significant immune response was seen in animal models. Several experiments were done which not only verified this, but also confirmed targeting capacity of some monoclonal antibodies specific to them. In a study done by Mannervik M et al., synthetic peptides of external envelope glycoprotein gp125 based on HIV-2 $2_{\text {SBL6669 }}$ were used to recognize its continuous antigenic sites. It verified seroreactivity to few distinct linear sites on gp125 analogous to HIV-1 gp120 in case of molecular arrangement (Marcelino et al. 2006). In another investigation, neutralizing Ab's targets for HIV-2 glycoprotein were mapped strictly considering the function of V3 region. Two discrete immunogenic sites were identified, first in the area with the conserved motif Phe-His-Ser (amino acid 315-317) second in the immediacy of the $\mathrm{COOH}$ terminal cysteine Trp-Cys-Arg (amino acid 329-331). It was concluded that these two can possibly interact as a single discontinuous site representing the importance of V3 (Andersson 2001). These immunogenic sites in V3-loop were further characterized and the significance of different configurations of peptides corresponding to this region was studied and attained outcomes maintained the hypothesis that the well conserved motifs of the HIV-2 ${ }_{\text {SBL6669 }}$ V3 region i.e. FHSQ and WCR are crucial targets for neutralizing antibodies. These motifs can play a vital role for the designing of a potential HIV-2 vaccine (Dimonte et al. 2011; Morner et al. 1999).

On the other hand the role of humoral immunity in the evolution of the $\mathrm{HIV}-2$ env $\mathrm{C} 2 \mathrm{~V} 3 \mathrm{C} 3$ regions was examined in the context of their antibody response (IgG and IgA) against it. IgG antibody against C2V3C3 efficiently restricted viral population and escape while IgA successfully targeted C3 region (Borrego et al. 2008). Recently molecular, evolutionary and structural comparison of the these envelope regions from both HIV-1 and HIV-2 was done which suggested that in HIV-2 the V3 loop is much less exposed than $\mathrm{C} 2$ and $\mathrm{C} 3$ due to a physical interaction with both whereas its conserved nature is constant with lack of immunodominancy in vivo (Barroso et al. 2011).

The capacity of antibodies against such conserved domains was explored by generating them in rabbits against HIV-2 V2 and V3 regions to interact with glycosylated and deglycosylated protein, to hinder with gpl05$\mathrm{CD}_{4}$ interface. It revealed that V2 and V3 regions are not directly involved in the gp105 binding site for the $\mathrm{CD}_{4}$ receptor (Babas et al. 1994). The production and characterization of MAbs (monoclonal antibodies) 
against these V3 and $\mathrm{C} 3$ regions of the gp120 of HIV2ROD suggested that the V3 region of HIV-2 has a similar function to that of HIV-1 in the infection process differing from earlier result which indicated lack of immunodominancy of $\mathrm{V} 3$ and specified that V3 sequence of HIV-2 may be a useful target in an animal model for HIV vaccine development (Matsushita et al. 1995). In addition, the neutralization capacity of the purified anti HIV-2 V3 MAbs i.e. conformation-sensitive (3C4) and a linear site-specific (7C8) and their respective papain-generated Fab fragments suggested that whole 7C8 and 3C4 MAbs were sterically hindered from neutralizing HIV-2. Alternatively the smaller size of Fab fragments capably accessed the virion surface V3 region (Sourial \& Nilsson 2008). Further proceeding in this direction, the crystal structure of the Fab fragment of 7C8 was presented for structural analysis which showed a deep and narrow highly hydrophobic antigen-binding cleft (Uchtenhagen et al. 2011).

Some distinctive details apart from the existence of conserved residues and generation of neutralizing antibodies against them were also revealed which might be valuable in some way or other. H. Akimoto et al., found that the envelope glycoprotein of HIV-2 (not of HIV-1), could bind to CD4 and CD8 molecules on T cells $\alpha$ chain (but not the P-chain) and induce phosphorylation of protein tyrosine kinase $\mathrm{p} 56^{1 \mathrm{ck}}$ (lymphocyte specific protein tyrosine kinase) in $\mathrm{CD} 8+\mathrm{T}$ cells. Also production of $\beta$-chemokines in response to HIV-2 envelope glycoprotein was significantly higher as compared to the response to HIV-1 envelope glycoprotein which was related to signal transduction into $\mathrm{CD} 8+\mathrm{T}$ cells and the resultant $\beta$-chemokines production in HIV-2 infection. This might explain the difference in virulence and disease manifestations between HIV-1 and HIV-2 infection (Cavaleiro et al. 2000).

Apart from envelope region gag was demonstrated to be most immunogenic specifically p26 region. The steady rapport between Gag specific immune responses and viral regulation indicated that, $\mathrm{T}$ cell responses are crucial in determining the better outcome of HIV-2 infection which may add to the understanding of relation between HIV-2 controlled infection and protective immunity for the design of HIV vaccine (Leligdowicz et al. 2007). Comparison of homologous and cross reactive Gag-specific T-cell responses between HIV-1 and HIV-2 infected patients for their gag peptides revealed that homologous Gag-specific T-cell responses were broader and stronger in HIV-2 infected patients as compared to HIV-1. In contrast cross reactive T-cell response was narrower and weaker in HIV-2 as compared to HIV-1 infected patients. This cross reactive response indicated HIV-1/HIV-2 Gag sequence similarities. Thus HIV-2specific T-cell responses control HIV-2 replication restraining viral diversification (Jennes et al. 2008). The capsid region of Gag may be better processed and presented on MHC in contrast to other viral proteins moreover antigens from this region, might be more exposed to be presented as capsid, is generally expressed in higher levels (Chertova et al. 2006). A further examination reported another strategy for HIV-2 targeting. Genomic RNA dimerisation is facilitated by a sequence positioned within the Psi region and that dimerisation may certainly be linked to viral packaging thus dimerisation defective viruses will be deficient in virion maturation and infectivity, possibly presenting new targets for HIV-2 replication inhibition (L'Hernault et al. 2007).

These essential demonstrations indicate cross reactivity, strong antigenicity by conserved domains especially V3, antibody response against them and generation of anti-HIV-2 V3 mouse MAbs i.e. 3C4 and 7C8. Also the difference in signal transduction in HIVs, gag specific T-cell responses and dimerisation defective HIV-2 (deficient in maturity and infectivity) give minute details about HIV-2 which can prove stepping stones while aiming it and AIDS. But these essentials alone can't be sufficient, as some novel strategic effort which can use the above facts in a quicker way for rapid prediction of vaccine, is the need of the hour.

\section{Future Aspects}

The search for an effective AIDS vaccine is the most daunting task because of the variable and divergent characteristic of the virus along with extremely long and time taking protocols for vaccine development which calls for a minimum duration of 6-10 years. Till today vaccine development program has reached up to phase 3 trials for HIV-1 but no validated vaccine against HIV-1/ HIV-2 has been developed. The difficult and deficient character of these approaches is an obvious obstacle towards developing new vaccine.

Application of reverse vaccinology can be a possible strategy to overcome the aforementioned obstacles and surmount these challenges. It offers a promising vaccine development approach starting with the prediction of vaccine targets by bioinformatics scrutiny of pathogenic genome sequences (Rappuoli 2000). Predicted protein targets for instance, envelope protein etc. are chosen on the basis of desirable features after which normal wet laboratory trials could be carried out for testing the selected targets (Pizza et al. 2000; Rappuoli 2000) which reduces both time and cost of development. Also, other upcoming fields of vaccine research like vaccinomics including pharmacogenomics, pharmacogenetics as well as bioinformatics has proved beneficial in novel vaccine target prediction for extremely variable pathogens (Sirskyj et al. 2011). Moreover, synthetic peptides could be designed resembling the immunogenic or conserved domains of hyper variable 
pathogens and could be tested via the series of new emerging softwares for immune responses.

In one such study, two computer-driven methods for improving epitope-driven HIV vaccines: the Epi-Assembler, for deriving "immunogenic consensus sequences" (ICS) epitopes from multiple viral variants, and Vaccine CAD, which reduces junctional immunogenicity between epitopes for insertion in a DNA expression vector, were selected. They were used for selection and construction of novel "immunogenic consensus sequence" $T$ cell epitopedriven HIV vaccines (De Groot et al. 2005). Further computational modeling was applied for recognition of chimeric HRV (Human Rhinovirus type 14) constructs. They preferentially displayed the epitope in the same $\beta$ turn conformation as already depicted in the crystal structure of complex with 2 F5 and chimeric HRV displaying the 2F5 epitope of HIV-1 gp41 (called ELDKWA after its core sequence). It signified the prospect of eliciting protective immune responses (Lapelosa et al. 2009).

Many web based servers and softwares have been developed in the recent past which can efficiently predict epitopes and consensus sequence proving to be a quantum leap in the direction of vaccine development. $M H C P E P$ is a curated database comprising over 4000 peptide sequences known to bind MHC molecules. Entries are compiled from published reports as well as from direct submissions of experimental data (De Groot et al. 2002). PEPVAC (Promiscuous EPitopebased VACcine), optimized for the formulation of multi-epitope vaccines with broad population coverage
(Reche \& Reinherz 2005). Vaxign is the web-based vaccine design system for prediction of vaccine targets based on genome sequences using the strategy of reverse vaccinology. Predicted features comprise of protein sub cellular location, transmembrane helices, adhesion probability, conservation to human and/or mouse proteins, sequence exclusion from the genome (s) of nonpathogenic strain(s), and epitope binding to MHC class I and class II (He et al. 2010). Several other algorithms and databases for vaccine prediction are (Sirskyj et al. 2011):

- EpiMatrix (EpiVax Inc): Predicts epitopes for over numerous MHC class I and II alleles.

- BlatiMer: Automated BLAST search tool.

- Conservatrix: Finds conserved epitopes.

- PAP: Predicts protein sequences which can be antigenic by generating an antibody response

- SYFPEITHI: Database having numerous peptide sequences showing binding affinity with MHC class I and II molecules.

Modern strategies using in silico approaches will definitely be more quick, cost effective and may prove worthy in finding vaccine targets for HIV-2.

\section{Conclusion}

HIV-2 is slow progressing, less virulent and less mortal as compared to HIV-1. But certain striking features make it a promising vaccine candidate for targeting both HIV-1 \& 2

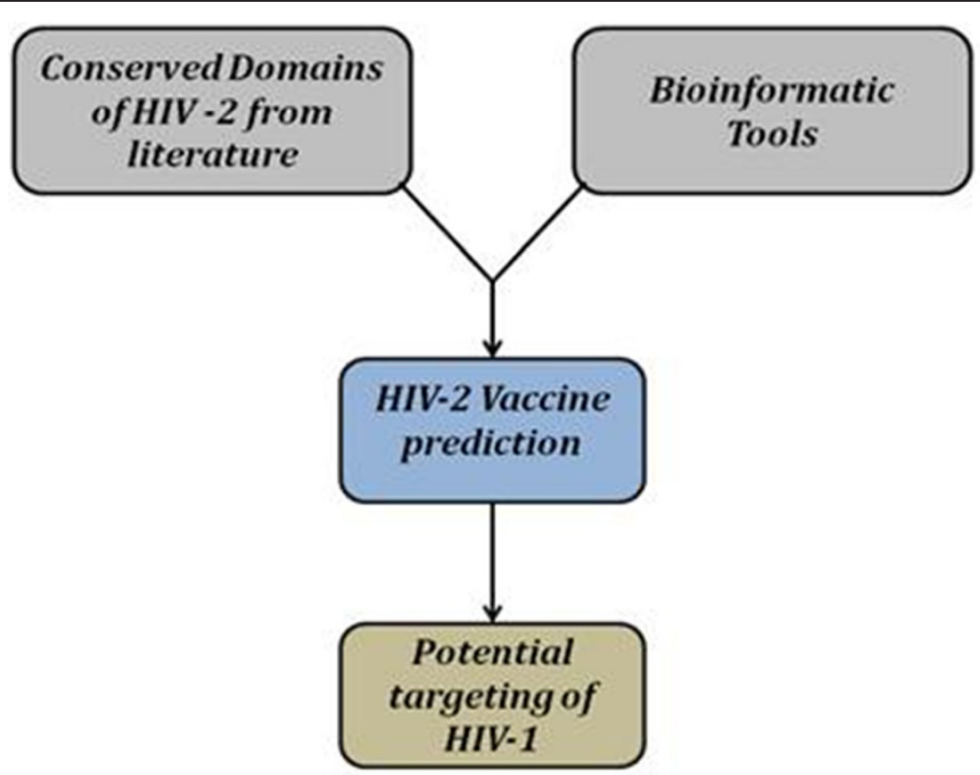

Figure 3 Application of Bioinformatics tools for HIV-2 and AIDS vaccine prediction: HIV-2 infected individuals exhibit cross protection to HIV-1 and hence HIV-2's conserved genomic regions could be utilized for targeting HIV-1 also. Bioinformatic tools, web servers like epitope prediction tools and other softwares can ease this task and hence can make the approach novel, rapid and effective for AIDS vaccine development 
such as its cross reactivity to HIV-1, spontaneous control of HIV-1 in African monkeys (believed to be ancestors of HIV-2), existence of certain extremely conserved domains in it against which neutralizing antibody response has been observed i.e. envelope proteins as well as gag. Thus detailed considerations of $\mathrm{HIV}-2$ can guide us towards a profound understanding of both viruses which can prove a landmark for design of a competent vaccine for AIDS

But conventional approaches are not entirely capable of dealing with various complications that arise during the development of new vaccines. Therefore the future of vaccine prediction lies in the union of current approaches like reverse vaccinology, vaccinomics by means of bioinformatics tool, web servers and softwares along with conventional approaches (Figure 3). This unification of existing conventional approaches with the above mentioned new strategies for predicting vaccine against HIV-2 will certainly be helpful in the lane of vaccine development against HIV-1 and AIDS which undeniably will be a future benediction to mankind.

\section{Competing interest}

The authors declare that they have no conflict of interest.

\section{Acknowledgement}

I would like to thank my parents as well. Also I heartily acknowledge Mr. Gagan Flora who had played a major role in correcting and editing the manuscript. Last but not the least I am thankful to my Friends and Almighty.

Received: 20 October 2012 Accepted: 8 January 2013

Published: 11 January 2013

\section{References}

Adam MN, Abdoulaye Dieng S, Jean-Louis S, Seema Thakore M, Souleymane M, Kanki P (2007) Direct Evidence of Lower Viral Replication Rates In Vivo in Human Immunodeficiency Virus Type 2 (HIV-2) Infection than in HIV-1 Infection. J Virol 81:5325-5330

Amadi K, Sabo AM, Ogunkeye OO, Oluwole FS (2008) Thyroid hormone: a "prime suspect" in human immunodeficiency virus (HIV/AIDS) patients? Nigerian Journal of Physiological Sciences: official publication of the Physiological Society of Nigeria 23:61-66

Andersson S, Makitalo B, Thorstensson R, Franchini G, Tartaglia J, Limbach K, Paoletti E, Putkonen P, Biberfeld G (1996) Immunogenicity and protective efficacy of a human immunodeficiency virus type 2 recombinant canarypox (ALVAC) vaccine candidate in cynomolgus monkeys. J Infect Dis 174:977-985 Andersson S (2001) HIV-2 and the Immune Response. AIDS Rev 3:11-23

Babas T, Benichou S, Guetard D, Montagnier L, Bahraoui E (1994) Specificity of antipeptide antibodies produced against $\mathrm{V} 2$ and $\mathrm{V} 3$ regions of the external envelope of human immunodeficiency virus type 2. Mol Immunol 31:361-369

Bakhanashvili M, Hizi A (1992) Fidelity of the RNA-dependent DNA synthesis exhibited by the reverse transcriptases of human immunodeficiency virus types 1 and 2 and of murine leukemia virus: mispair extension frequencies. Biochemistry 31:9393-9398

Barroso H, Borrego P, Bartolo I, Marcelino JM, Familia C, Quintas A, Taveira N (2011) Evolutionary and structural features of the C2, V3 and C3 envelope regions underlying the differences in $\mathrm{HIV}-1$ and $\mathrm{HIV}-2$ biology and infection. PLOS One 6:e14548

Belec L, Tevi-Benissan C, Dupre T, Mohamed AS, Prazuck T, Gilquin J, Kanga JM, Pillot J (1996) Comparison of cervicovaginal humoral immunity in clinically asymptomatic (CDC A1 and A2 category) patients with HIV-1 and HIV-2 infection. J Clin Immunol 16:12-20

Bernstein A (2010) The Council of the Global HIV Vaccine Enterprize (2010, September) 'The 2010 scientific strategic plan of Global HIV Vaccine Enterprize'. Nat Med 16:981-988
Borrego P, Marcelino JM, Rocha C, Doroana M, Antunes F, Maltez F, Gomes P, Novo C, Barroso H, Taveira N (2008) The role of the humoral immune response in the molecular evolution of the envelope $\mathrm{C}_{2}, \mathrm{~V} 3$ and $\mathrm{C} 3$ regions in chronically HIV-2 infected patients. Retrovirology 5:78

Cavaleiro R, Sousa AE, Loureiro A, Victorino RM (2000) Marked immunosuppressive effects of the HIV-2 envelope protein in spite of the lower HIV-2 pathogenicity. AIDS 14:2679-2686

Chanock RM, Lerner RA, Brown F (1987) Vaccines 87: modern approaches to new vaccines: prevention of AIDS and other viral, bacterial, and parasitic diseases. Cold Spring Harbor Laboratory, New York

Chen Z, Telfier P, Gettie A, Reed P, Zhang L, Ho DD, Marx PA (1996) Genetic characterization of new West African simian immunodeficiency virus SIVsm: geographic clustering of household-derived SIV strains with human immunodeficiency virus type 2 subtypes and genetically diverse viruses from a single feral sooty mangabey troop. J Virol 70:3617-3627

Chertova E, Chertov O, Coren LV, Roser JD, Trubey CM, Bess JW Jr, Sowder RC 2nd, Barsov E, Hood BL, Fisher RJ, Nagashima K, Conrads TP, Veenstra TD, Lifson JD, Ott DE (2006) Proteomic and biochemical analysis of purified human immunodeficiency virus type 1 produced from infected monocytederived macrophages. J Virol 80:9039-9052

Clavel F, Guetard D, Brun-Vezinet F, Chamaret S, Rey MA, Santos-Ferreira MO, Laurent AG, Dauguet C, Katlama C, Rouzioux C et al (1986) Isolation of a new human retrovirus from West African patients with AIDS. Science 233:343-346

De Cock KM, Adjorlolo G, Ekpini E, Sibailly T, Kouadio J, Maran M, Brattegaard K, Vetter KM, Doorly R, Gayle HD (1993) Epidemiology and transmission of HIV2. Why there is no HIV-2 pandemic. JAMA 270:2083-2086

De Groot AS, Sbai H, Aubin CS, McMurry J, Martin W (2002) Immuno-informatics: Mining genomes for vaccine components. Immunol Cell Biol 80:255-269

De Groot AS, Marcon L, Bishop EA, Rivera D, Kutzler M, Weiner DB, Martin W (2005) HIV vaccine development by computer assisted design: the GAIA vaccine. Vaccine 23:2136-2148

de Silva TI, Cotten M, Rowland-Jones SL (2008) HIV-2: the forgotten AIDS virus. Trends Microbiol 16:588-595

Dimonte S, Svicher V, Salpini R, Ceccherini-Silberstein F, Perno CF, Babakir-Mina M (2011) HIV-2 A-subtype gp125c(2)-v(3)-c(3) mutations and their association with CCR5 and CXCR4 tropism. Arch Virol 156:1943-1951

Fenyo EM, Putkonen P (1996) Broad cross-neutralizing activity in serum is associated with slow progression and low risk of transmission in primate lentivirus infections. Immunol Lett 51:95-99

Gao F, Yue L, Robertson DL, Hill SC, Hui H, Biggar RJ, Neequaye AE, Whelan TM, Ho DD, Shaw GM et al (1994) Genetic diversity of human immunodeficiency virus type 2: evidence for distinct sequence subtypes with differences in virus biology. J Virol 68:7433-7447

Girard M, Valette L (1988) Retroviruses of Human A.I.D.S. and Related Animal Diseases. Pasteur Vaccins 219-220

Greenberg AE (2001) Possible protective effect of HIV-2 against incident HIV-1 infection: review of available epidemiological and in vitro data. AIDS 15:2319-2321

Guyader M, Emerman M, Sonigo P, Clavel F, Montagnier L, Alizon M (1987) Genome organization and transactivation of the human immunodeficiency virus type 2. Nature 326:662-669

He Y, Xiang Z, Mobley HLT (2010) Vaxign: The First Web-Based Vaccine Design Program for Reverse Vaccinology and Applications for Vaccine Development. J Biomed Biotechnol 2010 1-15

Hizi A, Tal R, Shaharabany M, Loya S (1991) Catalytic properties of the reverse transcriptases of human immunodeficiency viruses type 1 and type 2. J Biol Chem 266:6230-6239

Jennes W, Camara M, Dieye T, Mboup S, Kestens L (2008) Higher homologous and lower cross-reactive Gag-specific T-cell responses in human immunodeficiency virus type 2 (HIV-2) than in HIV-1 infection. J Virol 82:8619-8628

Kanki PJ, Meloni ST (2004) Biology and Variation in HIV-2 and HIV-1. Science and Treatment of HIV Infection 1-24

L'Hernault A, Greatorex JS, Crowther RA, Lever AM (2007) Dimerisation of HIV-2 genomic RNA is linked to efficient RNA packaging, normal particle maturation and viral infectivity. Retrovirology 4:90

Lapelosa M, Gallicchio E, Arnold GF, Arnold E, Levy RM (2009) In silico vaccine design based on molecular simulations of rhinovirus chimeras presenting HIV-1 gp41 epitopes. J Mol Biol 385:675-691

Laurén A, Thorstensson R, Fenyö EM (2006) Comparative studies on mucosal and intravenous transmission of simian immunodeficiency virus (SIVsm): the 
kinetics of evolution to neutralization resistance are related to progression rate of disease. J Gen Virol 87:595-606

Leligdowicz A, Yindom LM, Onyango C, Sarge-Njie R, Alabi A, Cotten M, Vincent T, da Costa C, Aaby P, Jaye A, Dong T, McMichael A, Whittle H, RowlandJones S (2007) Robust Gag-specific T cell responses characterize viremia control in HIV-2 infection. J Clin Invest 117:3067-3074

Levy JA (1993) Pathogenesis of human immunodeficiency virus infection. Microbiol Rev 57:183-289

Mandell GL, Bennett JE, Dolin R (2009) Mandell, Douglas, and Bennett's Principles and Practice of Infectious Diseases. Elsevier Health Sciences. Philadelphia, PA: Churchill Livingstone

Marcelino JM, Barroso H, Gonçalves F, Silva SM, Novo C, Gomes P, Camacho R, Taveira N (2006) Use of a New Dual-Antigen Enzyme-Linked Immunosorbent Assay To Detect and Characterize the Human Antibody Response to the Human Immunodeficiency Virus Type 2 Envelope gp125 and gp36 Glycoproteins. J Clin Microbiol 44:607-611

Marcelino JM, Borrego P, Rocha C, Barroso H, Quintas A, Novo C, Taveira N (2010) Potent and broadly reactive HIV-2 neutralizing antibodies elicited by a vaccinia virus vector prime-C2V3C3 polypeptide boost immunization strategy. J Virol 84:12429-12436

Matsushita S, Matsumi S, Yoshimura K, Morikita T, Murakami T, Takatsuki K (1995) Neutralizing monoclonal antibodies against human immunodeficiency virus type 2 gp120. J Virol 69:3333-3340

Morner A, Achour A, Norin M, Thorstensson R, Bjorling E (1999) Fine characterization of a V3-region neutralizing epitope in human immunodeficiency virus type 2. Virus Res 59:49-60

Pizza M, Scarlato V, Masignani V, Giuliani MM, Arico B, Comanducci M, Jennings GT, Baldi L, Bartolini E, Capecchi B, Galeotti CL, Luzzi E, Manetti R, Marchetti E, Mora M, Nuti S, Ratti G, Santini L, Savino S, Scarselli M, Storni E, Zuo P, Broeker M, Hundt E, Knapp B, Blair E, Mason T, Tettelin H, Hood DW, Jeffries AC, Saunders NJ, Granoff DM, Venter JC, Moxon ER, Grandi G, Rappuoli R (2000) Identification of vaccine candidates against serogroup B meningococcus by whole-genome sequencing. Science 287:1816-1820

Popper SJ, Sarr AD, Guèye-Ndiaye A, Mboup S, Essex ME, Kanki PJ (2000) Low Plasma Human Immunodeficiency Virus Type 2 Viral Load Is Independent of Proviral Load: Low Virus Production In Vivo. J Virol 74:1554-1557

Putkonen P, Bjorling E, Akerblom L, Thorstensson R, Lovgren K, Benthin L, Chiodi F, Morein B, Biberfeld G, Norrby E et al (1994) Long-standing protection of macaques against cell-free HIV-2 with a HIV-2 iscom vaccine. J Acquir Immune Defic Syndr 7:551-559

Rappuoli R (2000) Reverse vaccinology. Curr Opin Microbiol 3:445-450

Reche PA, Reinherz EL (2005) PEPVAC: a web server for multi-epitope vaccine development based on the prediction of supertypic MHC ligands. Nucleic Acids Res 33:W138-142

Reeves JD, Doms RW (2002) Human immunodeficiency virus type 2. J Gen Virol 83:1253-1265

Schim van der Loeff MF, Aaby P, Aryioshi K, Vincent T, Awasana AA, Da Costa C, Pembrey L, Dias F, Harding E, Weiss HA, Whittle HC (2001) HIV-2 does not protect against HIV-1 infection in a rural community in Guinea-Bissau. AIDS 15:2303-2310

Sirskyj D, Diaz-Mitoma F, Golshani A, Kumar A, Azizi A (2011) Innovative bioinformatic approaches for developing peptide-based vaccines against hypervariable viruses. Immunol Cell Biol 89:81-89

Smith SM, Christian D, de Lame V, Shah U, Austin L, Gautam R, Gautam A, Apetrei C, Marx PA (2008) Isolation of a new HIV-2 group in the US. Retrovirology 5:103

Sourial S, Warnmark A, Nilsson C, Bjorling E, Achour A, Harris RA (2005) Cloning, expression, and purification of HIV-2 gp125: A target for HIV vaccination. Mol Biotechnol 30:155-162

Sourial S, Nilsson C (2008) HIV-2 neutralization by intact V3-specific Fab fragments. Virol J 5:96

Sousa AE, Carneiro J, Meier-Schellersheim M, Grossman Z, Victorino RMM (2002) CD4 T Cell Depletion Is Linked Directly to Immune Activation in the Pathogenesis of HIV-1 and HIV-2 but Only Indirectly to the Viral Load. J Immunol 169:3400-3406

Taylor RB (2003) Family Medicine: Principles and Practice Springer, New York

Uchtenhagen H, Friemann R, Raszewski G, Spetz AL, Nilsson L, Achour A (2011) Crystal structure of the HIV-2 neutralizing Fab fragment 7C8 with high specificity to the V3 region of gp125. PLoS One 6:e18767
Voss G, Kirchhoff F, Nick S, Moosmayer D, Gelderblom H, Hunsmann G (1992) Morphogenesis of recombinant HIV-2 gag core particles. Virus Res 24:197-210

Worobey M, Telfer P, Souquiere S, Hunter M, Coleman CA, Metzger MJ, Reed P, Makuwa M, Hearn G, Honarvar S, Roques P, Apetrei C, Kazanji M, Marx PA (2010) Island biogeography reveals the deep history of SIV. Science 329:1487

doi:10.1186/2193-1801-2-7

Cite this article as: Diwan et al: HIV-2 and its role in conglutinated approach towards Acquired Immunodeficiency Syndrome (AIDS) Vaccine Development. SpringerPlus 2013 2:7.

\section{Submit your manuscript to a SpringerOpen ${ }^{\circ}$ journal and benefit from:}

- Convenient online submission

- Rigorous peer review

- Immediate publication on acceptance

- Open access: articles freely available online

High visibility within the field

- Retaining the copyright to your article

Submit your next manuscript at $\gg$ springeropen.com 